\title{
Isquemia del pie derecho en un joven fumador
}

\section{Sr. Director:}

La enfermedad de Buerger o tromboangeitis obliterante es una enfermedad inflamatoria no ateroesclerótica y segmentaria de pequeños y medianos vasos descrita en 1879 por Von Winiwarter y que cursa con signos y síntomas de isquemia distal de extremidades. A continuación se describe el caso de un paciente afecto.

Paciente varón de 32 años de edad, búlgaro, fumador de medio paquete al día desde hace más de 10 años que consulta por presentar desde hacía tres semanas frialdad, palidez, parestesias y dolor en reposo del pie derecho con la exposición al frío, mejorando con el calor. En la exploración se objetivaba un pie derecho pálido, frío con hipoestesias y ausencia de pulso pedio, estando muy disminuido el tibial posterior. Los contralaterales también estaban disminuidos. Los test de laboratorio eran normales Se le 
realizó una angioresonancia de las extremidades inferiores, mostrando a nivel distal unos vasos de aspecto filiforme con oclusión proximal de ambas arterias tibiales anteriores y posteriores más marcados en la derecha, con un importante aumento de las arterias peroneas siendo éstos hallazgos compatibles con tromboangeitis obliterante o enfermedad de Buerger (Fig. 1). Se instauró tratamiento con prendas de abrigo sobre la extremidad, antiagregantes y abandono del tabaco presentando buena evolución.

La enfermedad de Buerger es una inflamación no ateroesclerótica, recurrente, segmentaria y obliterante de arterias y venas de pequeño y mediano calibre que afecta preferentemene a zonas distales de las extremidades (1). Afecta principalmente a varones fumadores, jóvenes con un alta incidencia en el este de Europa y en Asia. Se presenta como una isquemia de los dedos (dolor en reposo, debilidad o ausencia de pulso, palidez y frialdad de extremidad, parestesias), claudicación intermitente, pudiendo progresar hasta presentar úlceras dolorosas y gangrena. Las tromboflebitis superficiales y el fenómeno de Raynaud también pueden estar presentes. El diagnóstico diferencial hay que hacerlo con estados de hipercoagulabilidad, ateroesclerosis, conectivopatías y otras vasculitis (1). Los criterios clínicos de Shionoya son útiles para el diagnóstico (2).

Las técnicas de imagen muestran típicamente afilamientos arteriales, oclusiones o estenosis de los vasos, siendo éstos el resultado del daño vascular. Estos hallazgos son característicos pero no patognomónicos (1).

El tratamiento pasa por el abandono del tabaco como la medida más importante. También la exposición al frío o al calor, los traumatismos y las infecciones han de ser evitados. Los análogos de las prostaglandinas (ilioprost), la antiagregación y los vasodi-

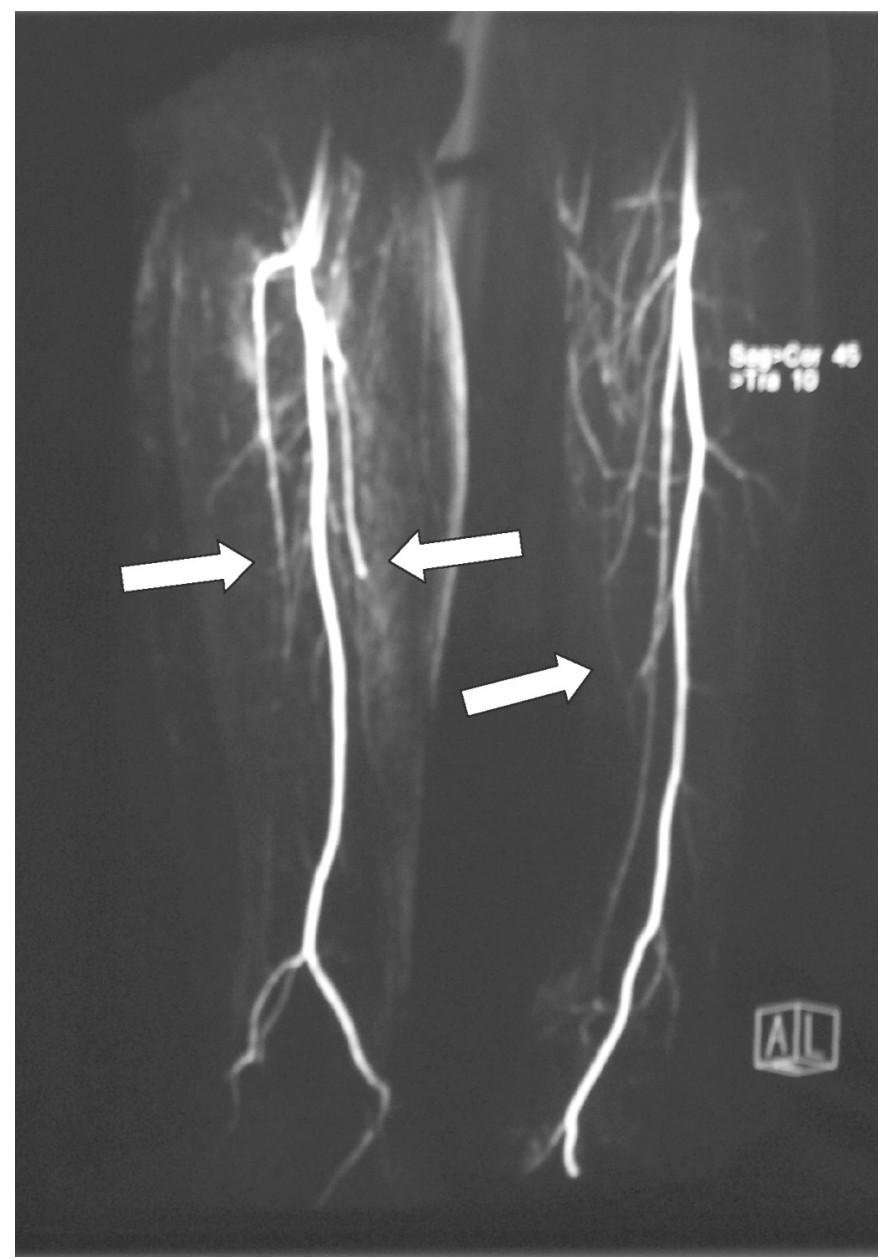

Fig. 1. Afilamiento y estenosis las de arterias tibiales latadores periféricos como la pentoxilifina pueden ser útiles. Tanto la terapia trombolítica, los corticoides como la revascularización quirúrgica, la simpatectomía o la implantación de un estimulador espinal no han mostrado un mayor beneficio y no suelen estar recomendadas $(1,3,4)$ si bien algún trabajo reciente ha mostrado algún beneficio en la microcirculación y en la ausencia de nuevas lesiones tróficas con este último método (5).

En resumen, hemos de sospechar una enfermedad de Buerger delante de un joven fumador sin otros factores de riesgo cardiovascular que presenta síntomas de isquemia distal en extremidades superiores o inferiores $(1,2)$.

\section{P. J. Marchena Yglesias, I. Buedo Sotos, L. P. de Benito Cor- dón, J. A. Nieto Rodríguez}

Servicio de Medicina Interna. Hospital Virgen de la Luz. Cuenca

1. Olin J. Thromboangiitis obliterans (Buerger's disease). N Engl J Med 2000; 343: 864-869.

2. Shionoya S. Diagnostic criteria of Buerger's disease. Int J Cardiol 1998; 66 (Supl. 1): S243-5.

3. Roncon de Alburquerque R, Castro E, Costa Lima J, Vale Pereira, Braga A. Enfermedad de Buerger. Casuística personal. Diagnóstico y tratamiento. An Cir Card Vasc 2001; 7: 110-116

4. Swigris JJ, Olin JW, Mekhail NA. Implantable spinal cord stimulator to treat the ischemic manifestations of thromboangiitis obliterans (Buerger's disease). J Vasc Surg 1999; 29: 928-35

5. Donas KP, Schulte S, Ktenidis K, Horsch S. The role of epidural spinal cord stimulation in the treatment of Buerger's disease. J Vasc Surg 2005; 41: $830-6$ 